\title{
Knowledge, self-efficacy, and practice among nurses for prevention of chronic low back pain in Arak, Iran, in 2014
}

\author{
Khorsandi M, $\mathrm{PhD}^{1}$, Sharafkhani N, MSc ${ }^{2 *}$, Shamsi M, $\mathrm{PhD}^{3}$, Ranjbaran M, MSc ${ }^{4}$ \\ 1- Asssociated Prof., Dept. of Health Education and Promotion, Health Faculty, Arak University of Medical Sciences, \\ Arak, Iran. 2- Faculty Member, Dept. of Health Education and Promotion, Health Faculty, Arak University of Medical \\ Sciences, Arak, Iran. 3- Assistant Prof., Dept. of Health Education and Promotion, Health Faculty, Arak University of \\ Medical Sciences, Arak, Iran. 4- Faculty Member, Dept. of Health Education, Health faculty, Arak University of \\ Medical Sciences, Arak, Iran.
}

\begin{abstract}
Received: February 2015, Accepted: April 2015

Background: Chronic low back pain (CLBP) is an important occupational injury. Musculoskeletal injuries, especially CLBP, are prevalent in the nurses, and can lead to reduced productivity, work absenteeism, and work disability.

The purpose of this study was to determine nurses' knowledge of the risk factors of low back pain (LBP) and their self-efficacy in coping with the risk factors, and to evaluate CLBP preventive behaviors in nurses.

Materials and Methods: This descriptive cross-sectional research was performed on 133 nurses selected randomly from 3 government hospitals affiliated with Arak University of Medical Sciences, Arak, Iran. The data collection tool was a questionnaire on demographic characteristics, knowledge, self-efficacy, and practice of the nursing staff in CLBP preventive behaviors. Data was analyzed using descriptive and analytical statistical methods and Pearson's correlation coefficient.

Results: The mean age of the nurses was $32.1 \pm 5$.3. Our findings showed that in terms of LBP the nursing staff had average level of knowledge with a mean score of $60.2 \pm 19.69$ out of 100 , average level of self-efficacy with a mean score of $55.9 \pm 10.6$ out of 100 , and poor practice with a mean score of $43.9 \pm 6.9$ out of 100 . The correlation between knowledge, and self-efficacy and practice was not significant, but self-efficacy showed a significant correlation with practice and being married $(\mathrm{P}<0.05)$.

Conclusions: According to our study, most participants lacked appropriate knowledge, selfefficacy, and practice with regard to CLBP preventive behaviors. Since back pain strongly affects the performance and service quality of the caregivers, the Iranian Ministry of Health and the related universities should make necessary educational and managerial arrangements to present educational programs aimed at CLBP prevention in the form of university courses, posters, films, workshops, and etcetera.
\end{abstract}

Keywords: Musculoskeletal Diseases, Nurses, Knowledge, Self Efficacy, Low Back Pain.

\section{Introduction}

Chronic low back pain (CLBP) is a discomfort in the back that may radiate to the calf, thigh, or buttocks and lasts for more that 3 months. Generally, low back pain (LBP) is categorized as specific and non-specific (1, 2). In theUS, LBP accounts for more than 18 million physician visits per year (3). LBP affects $70-80 \%$ of the population in their lifetime (4). According to the available statistics, LBP is the most common cause of activity limitation, the $5^{\text {th }}$ most frequent

Corresponding author: Naser Sharafkhani, Dept. of Health Education and Promotion, Health Faculty, Arak University of Medical Sciences, Arak, Iran.

Email: naser90sh@yahoo.com 
cause of hospitalization, and the $3^{\text {rd }}$ most common cause of surgery in the US (5).

The annual consequences of the LBP epidemic in the UK are 52.6 million days of work lost, making it the primary cause of work absenteesim among all diseases (12.5\%), waste of 2 million pounds, and loss of manpower. Each year, more than 2 million people seek advice about back pain from their general practitioners, 300,000 people receive out-patient consultation for their back pain in the hospital, and 50-1000 individuals become severely debilitated in a health domain of 250,000 population (6).

Regarding the prevalence of LBP, nursing is the $3^{\text {rd }}$ leading occupation (7). LBP is the most important occupational injury in nurses with a prevalence of $56-90 \%$, which is slightly higher than in other populations (8). The prevalence of LBP has been reported as $62 \%$ (9) and $49.4 \%$ in (10) some parts of Iran. In a study conducted on the nursing staff of Namazi and Shahid Faghihi Hospitals, Shiraz, Iran, in 1999, a $78.3 \%$ prevalence of occupational LBP was reported (11). About $98 \%$ of nurses move patients in such a way that applies a great amount of pressure on the lumbar vertebrae (12). Moreover, bending on the patient's bed during work and stretching the back increases the risk of back pain. In addition, inappropriate body postures, squatting, bending, prolonged standing, and a low nurse to patient ratio are other risk factors of back pain in nurses (12). Nurses who work in intensive care units are particularly prone to back pain due to their distinct work conditions $(13,14)$. Nurses are an efficient and effective part of any health system and are prone to the risk factors of back pain more than other occupational groups. They lose many work days due to back pain every year which lowers their productivity. However, back pain can be decreased using appropriate preventive measures, which requires the knowledgability of nurses on the principles of risk factor modification, like body posture during work, sitting, moving patients, and etcetera. This knowedgebility can only be achieved through education. Therefore, the aim of the present study was to evaluate the nursing staff's knowledge, self-efficacy, and practice in regard to the prevention of CLBP.

\section{Materials and Methods}

This descriptive cross-sectional study was conducted in Arak, Iran, in 2014. The minimum sample size was calculated at 126 persons considering a study conducted by Zakerian et al (15), using the following formula $\mathrm{n}=\frac{Z^{2}+S D^{2}}{d^{2}},(\mathrm{SD}=1, \mathrm{~d}=0.175$, and a CI of 95\%). However, in this study, we included 133 nurses who worked in government and educational hospitals (Amiral-Momenin, Amir Kabir, and Vali-e-Asr) affiliated with Arak University of Medical Sciences, Arak. Simple random sampling was used to select the nurses who had the inclusion criteria. The inclusion criteria consisted of BSc or higher degree in nursing, at least 1 year experience in clinical nursing, no musculoskeletal disorders (MSDs) in selfreports, no history of surgery on skeletal muscles, lack of pregnancy, and signing a written informed consent form. The exclusion criterion of the study was nurses' unwillingness to participate in the study. The research environment of this study consisted of the emergency, gynecology, surgical, internal, angiography, ENT (Ear, Nose, and Throat), neurosurgery, and orthopedic wards, operating rooms, CCUs, and adult and neonatal ICUs of the 3 hospitals. The data collection tool was a researcher-made questionnaire which had 24 questions in 4 sections. The sections consisted of demographic information, knowledge (8 questions such as: "What is the appropriate posture for sitting on a chair?"), self- 
efficacy, and a section containing a checklist on practice regarding CLBP preventive behaviors adopted from the Occupational Safety and Health Administration (OSHA) guidelines for nurses.

In the knowledge section, each correct answer scored 1 and each wrong answer scored 0 . The section on self-efficacy included 5 questions (for example: I am sure that I can exercise for at least four days per week for 30 minutes, in spite of my busy working schedule) on a 5-point Likert scale. The score of each question ranged from 1 to 5 (I totally agree $=5$, I agree $=4$, no idea $=3$, I disagree $=2$, and I totally disagree $=1$ ).

In the section containing questions on practice, a 22-item checklist assessed the principles of moving or lifting the patient or an object, keeping from bending on the patient or the work surface while working, applying the correct posture of standing or sitting on a chair, use of accessory tools and equipment, identification and illimination of ergonomic hazards of back pain, and appropriate work management to reduce exposure to CLBP risk factors on a 4-point Likert scale (never $=0$, seldom $=1$, often $=$ 2 , and always $=3$ ). The scores of the sections of knowledge, self-efficacy, and practice were finalized proportionate for 100 .

In data analysis, the nurses' scores of knowledge, self-efficacy, and practice regarding CLBP were categorized based on an expert panel in 3 different levels; poor (050), average (51-75), and acceptable (76100). The assumption on high and low levels of knowledge and practice was drawn from focus group discussion (16). The reliability of the questionnaire was assessed using Cronbach's alpha in a study on 30 nurses who were similar to the study population in terms of demographic characteristics. The Cronbach's alpha of the knowledge and selfefficacy sections, and practice checklist was $0.79,0.73$, and 0.72, respectively. Credible published articles on back pain were used to prepare the questionnaire about CLBP (1719). The questionnaires' content and face validity were evaluated through an interview with specialists in occupational medicine, ergonomics, occupational health, health education, nursing, and midwifery; their suggestion about the questions and required changes were observed. All data were entered into SPSS software (version 20, SPSS Inc, Chicago, IL, USA). Data analysis was conducted using descriptive statistics for normal data distribution and the results were confirmed using the Kolmogorov-Smirnov test and Pearson's correlation coefficient. The independent t-test was used to compare the mean scores of self efficacy, practice, and knowledge of the two groups (age, sex, marital status, and work experience).

\section{Results}

Questionnaires were given to 170 participants; 133 were fully completed and returned. The mean age of our participants was $32.1 \pm 5.3$ years and $76.6 \%$ of the nurses had 10 years of experience or less. Other demographic characteristics of the participants are presented in table 1 .

The mean score of the general knowledge of the participants on CLBP prevention was $60.2 \pm 19.69$ in the 133 nurses who completed the questionnaire. The mean score self-efficacy was $55.9 \pm 10.6$ out of 100 .

The mean score of the nurses' practice was $43.9 \pm$ 6.9. Moreover, 47 of the nurses (35.5\%) did not exercise at all, $83(62.4 \%)$ rarely exercised, 3 (2.3\%) exercised most often, and no one exercised constantly. Knowledge was not significantly correlated with self-efficacy and practice. Moreover, there was no significant relationship between knowledge and variables like age, marital status, employment status, work experience, level of education, and the duty station. Nevertheless, the correlation between self- 
efficacy and practice was significant $\quad(\mathrm{P}=0.027)$ (Table 2).

Table 1: Relative and absolute frequency of the demographic characteristics of the participants

\begin{tabular}{lccc}
\hline \multicolumn{2}{c}{ Demographic Characteristic } & umberN & Percent \\
\hline \multirow{2}{*}{ Sex } & Male & 11 & 8.3 \\
\cline { 2 - 4 } & Female & 122 & 91.7 \\
\hline \multirow{2}{*}{ Age } & Below 35 & 106 & 79.7 \\
\hline \multirow{2}{*}{ Education } & 35 and over & 27 & 20.3 \\
\cline { 2 - 4 } & BSc & 131 & 98.5 \\
\cline { 2 - 4 } & MSc or higher & 2 & 1.5 \\
\cline { 2 - 4 } & Less than 5 & 42 & 31.6 \\
\cline { 2 - 4 } Experience & $5-10$ & 60 & 45.1 \\
\cline { 2 - 4 } & $11-15$ & 11 & 8.3 \\
\cline { 2 - 4 } & $16-20$ & 6 & 10.5 \\
\hline \multirow{2}{*}{$\begin{array}{c}\text { Marital } \\
\text { Status }\end{array}$} & More than 20 & 50 & 37.5 \\
\hline \multirow{2}{*}{} & Single & 133 & 62.4 \\
\cline { 2 - 4 } & Married & 100 \\
\hline
\end{tabular}

Independent t-test showed a statistically significant difference between married and single groups $(\mathrm{P}=0.009)$ in terms of selfefficacy. The relationship of self-efficacy with variables like age, employment status, work experience, and level of education was not significant.

Table 2: Coefficient correlations of the knowledge level and selfefficacy with practice

\begin{tabular}{cccc}
\hline Variable & Knowledge & Self-efficacy & Practice \\
\hline Knowledge & 1 & & \\
\hline \multirow{2}{*}{ Self-efficacy } & $\mathrm{r}=0.01$ & 1 & \\
& $\mathrm{P}=0.87$ & & \\
\hline \multirow{2}{*}{ Practice } & $\mathrm{r}=0.03$ & $\mathrm{r}=0.19^{*}$ & 1 \\
& $\mathrm{P}=0.67$ & $\mathrm{P}=0.027$ & \\
\hline
\end{tabular}

\section{Discussion}

Regarding the first objective of our study, our findings showed an average level of knowledge among the nurses on CLBP preventive behaviors. The nurses' knowledge of the risk factors of CLBP and related issues was poor, which is in line with the results of a similar study performed by Choobineh et al. in Shiraz, Iran (20). In our study, the respondents had little knowledge on the correct posture of sitting on a chair and the risk factors of CLBP (49.6\% and 56.3\% correct answers, respectively). Nevertheless, their knowledge of back pain preventive behaviors and mechanical causes of CLBP was average $(66.1 \%$ and $64.6 \%$ correct answer, respectively).

The nurses also had poor knowledge of ergonomics principles, which is not congruent with the results of a study by Zakeriyan et al. who assessed the correlation of the knowledge of ergonomics and the 
conditions of the work place with MSDs in nurses and reported an average level of knowledge. They also suggested comprehensive training programs to increase the nurses' knowledge of ergonomic principles in the workplace (15).

Wongthanakit et al. suggested that in order to increase the level of LBP preventive behaviors, the hospital should promote knowledge about and positive attitude toward LBP preventive behaviors in nursing tasks as well as daily activities (21). However, Bigos et al. showed that ergonomics or back education, and reduced lifting programmes are not effective (22). This finding is supported that of Smedley et al. who found that an ergonomic program provided no improvement in patient handling activities or the prevalence of musculoskeletal symptoms (23).

Berthelette et al. performed a study to evaluate the effect of an ergonomic training program on back pain prevention and reported that interventional programs should start before the incidence of the problems (24).

No significant relationship was observed between knowledge and practice. According to Mahmoudishan, knowledge by itself does not result in good practice; attitudes should change and the structure of the beliefs must be scientific (25). Single preventative measures, such as education programs, have largely been unsuccessful in reducing back injuries or back pain among nurses $(26,27)$.

A significant relationship was observed between self-efficacy and practice, but the correlation of knowledge with variables such as age, marital and employment status, work experience, level of education, and the duty station (work settings) was not significant. In studies performed by Branney et al. and Engkvist et al., no significant correlation was reported between sex, marital status, work experience, and back pain $(28,29)$. However, in a study conducted by Ramezani Badr et al., the correlation of back pain with age, work experience, marital status, and duty station was significant (30).

The second objective of our study was to evaluate the nurses' self-efficacy in LBP preventive behaviors, which was found to be average with a mean score of $55.9 \pm 10.6$ out of 100 . Of all the participants, 36 nurses (27.1\%) scored poorly, 91 nurses (68.4\%) scored average, and 6 nurses (4.5\%) scored well. Self-efficacy acts as an intermediary between knowledge and behavior and is a prerequisite for behavioral change. It is in fact the confidence that a person has in his abilities to perform a certain behavior (31). Fongsri et al. performed a study to evaluate the effects of a self-efficacy promoting program for the prevention of LBP in patient transfer workers in Bangkok (32). They found that after the interventions, there was a significant correlation between perceived self-efficacy and LBP preventive behaviors. Therefore, the implementation of selfefficacy training programs for the prevention of back pain were suggested in other work groups (32). Ng'uurah et al. reported that elevated self-efficacy levels allowed participants in their study to decide on more challenging settings, explore their environment, or create a new environment that would facilitate their wellness such as joining health clubs for healthy lifestyle changes regardless of LBP (33).

Regarding the third objective, our findings showed that the nurses' overall practice, with a mean score of $43.9 \pm 6.9$, was poor. In our study population, $113(85 \%)$ had poor practice scores, 20 (15\%) had average scores, and no one had good practice scores. The results of the study performed by Choobineh et al. showed that a limited number of nurses acquired a favorable score in adopting necessary corrective actions in order to lower the prevalence of back pain, which is congruent with the findings of our study (20). 
Regarding the effect of exercise on back pain, reports suggest that regular exercise reduces the risk of back pain, indicating that physical exercise is the most important protective factor which reduces the odds of back pain by $60 \%$. The odds ratio is almost similar in the multivariate model, suggesting that the protective effect of exercise is almost independent of other factors. Different studies show that the prevalence of back pain is lower in individuals who exercise regularly (34). Findings from systematic reviews of trials into the prevention of LBP show that only exercise interventions seem to be effective (35). Since the nurses had a poor practice score in terms of exercise, they should be encouraged to exercise through appropriate plans and programs in order to strengthen their back muscles. The relationship of knowledge and practice was not significant in our study. Nevertheless, Collins et al., in a prospective 6-year study, showed that educational programs on the principles of patient handling and movement, correct use of assistive devices like lifting equipment, education of the OSHA guidelines of patient handling and movement, and assuming correct posture while handling patients lowered musculoskeletal injuries in nurses (36). Therefore, educational programs on back pain prevention are an inseparable part of prevention strategies for back pain.

Stetler believes that to prevent musculoskeletal injuries, multidimensional interventions should at least contain removal of the risk factors, along with engineering, managerial, and educational control (37). It should be noted that there are different tasks in the nursing profession which may cause musculoskeletal injuries if performed repeatedly and as a routine throughout their professional life. In most of the studies, education of the correct body mechanics during work, and modification of the occupational physical pressure with regard to ergonomic processes like the use of assistive devices (which both lower physical tension and injury in nurses and bring more comfort to patients) have been proposed as preventive strategies for MSDs in nurses (38-42).

\section{Conclusion}

According to our study, most nurses lacked appropriate knowledge, self-efficacy, and practice with regard to CLBP preventive behaviors. Therefore, since back pain strongly affects the performance and service quality of the caregivers, the Iranian Ministry of Health and the related universities should make necessary educational and managerial arrangements to present educational programs aimed at CLBP prevention in the form of university courses, posters, films, workshops, and etcetera.

\section{Acknowledgement}

This research was funded by Arak University of Medical Sciences. The authors wish to thank the Deputy of Education and Research of the university, the director of the research affairs, and the nurses who participated in the study.

Conflict of interest: Non declared

\section{References}

1. Airaksinen O, Brox JI, Cedraschi C, Hildebrandt J, Klaber-Moffett J, Kovacs F, et al. Chapter 4. European guidelines for the management of chronic nonspecific low back pain. Eur spine J 2006;15(2):192-300.

2. Roffey DM, Wai EK, Bishop P, Kwon BK, Dagenais S. Causal assessment of workplace manual handling or assisting patients and low back pain: results of a systematic review. Spine J 2010; 10(7):639-51.

3. Rucker KS, Weinstein SM, Cole AJ. Low back pain: a symptom-based approach to diagnosis and treatment. United States: Butterworth-Heinemann 2000. 
4. Frank JW, Kerr MS, Brooker AS, DeMaio SE, Maetzel A, Shannon HS, et al. Disability resulting from occupational low back pain. Part I: What do we know about primary prevention? A review of the scientific evidence on prevention before disability begins. Spine 1996; 21(24):2908-17.

5. Andersson GB. Epidemiological features of chronic low-back pain. Lancet 1999; 354(9178):581-5.

6. Fordyce WE. Back pain in the workplace: management of disability in nonspecific conditions: a report of the task force on pain in the workplace of the International Association for the Study of Pain. $6^{\text {th }}$ ed. Seattle: IASP press 1995.

7. Yip Y. A Study of work Stress, patient handing activities and the risk of Low back pain among nurses in Hong Kong. J Adv Nurs 2001; 36(6):794-803.

8. Knibbe J, Friele R. Prevalence of back pain and characteristics of the physical workload of community nurses. Ergonomics 1996; 39(2):186-98.

9. Mohseni Bandpei M, Fakhri M, Ahmad Shirvani M, Bagheri Nesami M, Khalilian A. Epidemiological aspects of low back pain in nurses. Journal of Babol University of Medical Sciences 2005; 7(2):35-40.

10. Sadeghian F, kalalian Moghaddam $H$, Javanmard M, Khosravi A, Adelnia S. An epidemiological survey of Low back pain and its relationship with occupational and personal factors among nursing personnel at hospitals of Shahrood Faculty of Medical Sciences. Iranian South Medical Journal 2005; 8(1):75-82.

11. Simozar I, Derakhshan A, Sadeghi H, Zare N. Incidence of Low Back Pain in Nursing Staff of Namazi and Faghihi Hospital and its Relationship with Their Knowledge of Predisposing Factors in the Workplace. [MSc Thesis]. Shiraz: University of Medical Sciences; 1999.

12. Bernard BP. Musculoskeletal disorders and workplace factors: a critical review of epidemiologic evidence for work-related Musculoskeletal disorders of the neck, upper extremities, and low back. Columbia Parkway: Publications Dissemination 1998

13. Ando $S$, Ono $Y$, Shimaoka $M$, Hiruta $S$, Hattori Y, Hori F, et al. Associations of self estimated workloads with musculoskeletal symptoms among hospital nurses. Occup Environ Med 2000; 57(3):211-6.

14. Chiou WK, Wong MK, Lee YH. Epidemiology of low back pain in Chinese nurses. Int J Nurs Stud 1994; 31(4):361-8.

15. Zakeriyan SA, Monazam MR, Habibi Mohraz M, Soltani Gerdfaramarzi R, Asghari M, Ghaemiyan N. Relationship between knowledge of ergonomics and work-place conditions with musculoskeletal disorders among nurses of two Iranian hospitals.
Community Occupational Medicine 2012; 3(4):19-25.

16. Barua A. Methods for Decision-Making in Survey Questionnaires based on likert scale. Journal of Asian Scientific Research 2013; 3(1):35-8.

17. Chao EL, Henshaw JL. Guidelines for Nursing Homes Ergonomics for the Prevention of Musculoskeletal Disorders. United States: Occupational Safety Health Administration (OSHA) 2009.

18. Sherehiy B, Karwowski W, Marek T. Risk factors for work-related musculoskeletal disorders in the nursing profession: a review. Ergonomia: An international Journal of Ergonomics and Human Factors 2004; 26(1):19-48.

19. Nelson AL, Motacki K, Menzel NN. The illustrated guide to safe patient handling and movement. New York: Springer Publishing Company 2009.

20. Choobineh A, Taghirpour-kazerooni MB, Tabatabai SHR, Kamalinia M. study of nurses' Knowledge on low back pain risk factors in hospitals of Shiraz University of Medical Sciences. Journal of Health \& Safety at Work 2012;2(1):55-62.

21. Wongthanakit S, Tongvichean S, Kalampakorn S, Kaewboonchoo O. Factors related to low back pain preventive behaviors among nurses in governmental hospitals, Nonthaburi Province. Journal of Public Health 2005; 35(2):109-18.

22. Bigos SJ, Holland J, Holland C, Webster JS, Battie M, Malmgren JA. High-quality controlled trials on preventing episodes of back problems: systematic literature review in working-age adults. Spine J 2009; 9(2):147-68.

23. Smedley J, Poole J, Waclawski E, Stevens A, Harrison J, Buckle $P$, et al. Assessing investment in manual handling risk controls: a scoring system for use in observational studies. Occup Environ Med 2005; 62(1):635.

24. Berthelette D, Leduc N, Bilodeau H, Durand MJ, Faye C. Evaluation of the implementation fidelity of an ergonomic training program designed to prevent back pain. Appl Ergon 2012; 43(1):239-45.

25. Mahmoudi GR, Hossani SA. Knowledge, attitude and performance of barbers about AIDS prevention. Journal of Gorgan University of Medical Sciences 2000; 2(1):26-32.

26. Feldstein A, Valanis B, Vollmer W, Stevens $\mathrm{N}$, Overton $\mathrm{C}$. The back injury prevention project pilot study: Assessing the effectiveness of back attack, an injury prevention program among nurses, aides, and orderlies. J Occup Med 1993; 35(2):114-20.

27. Maul I, Läubli T, Klipstein A, Krueger H. Course of low back pain among nurses: A 
longitudinal study across eight years. Occup Environ Med 2003; 60(7):497-503.

28. Branney J, Newell D. Back pain and associated healthcare seeking behaviour in nurses: A survey. Clinical Chiropractic 2009; 12(4):130-43.

29. Engkvist IL, Kjellberg A, Wigaeus HE, Hagberg M, Menckel E, Ekenvall L. Back injuries among nursing personnelidentification of work conditions with cluster analysis. Saf Sci 2001; 37(1):1-18.

30. Ramezani-Badr F, Nikbakht A, Mohammadpour A. Low-back pain prevalence and its risk factors in nurses. Iranian Journal Nursing Research 2006; 1(2):37-42.

31. Saffari M, Shojaee D, Ghofranipour F, Heidarnia A. Health education and promotion: Theory, models and methods. Tehran: sobhan 2002.

32. Fongsri U, Rawiworrakul T, Kaewboonchoo $\mathrm{O}$, Kolladarungkri T. Effects of a Selfefficacy Promoting Program for Low Back Pain Prevention in Patient Transfer Workers, at a University Hospital in Bangkok. Asia journal of Publish Health 2011; 2(2):47-53.

33. Ng'uurah JN. Health education needs among individuals with low back pain. [MSc thesis]. suburb of Cape Town, South Africa: University of the Western Cape; 2004.

34. Mandel JH, Lohman W. Low back pain in nurses: the relative importance of medical history, work factors, exercise, and demographics. Res Nurs Health 1987; 10(3):165-70.

35. Balagué F, Mannion AF, Pellisé F, Cedraschi C. Non-specific low back pain. Lancet 2012; 379(9814):482-91.

36. Collins JW, Wolf L, Bell J, Evanoff B. An evaluation of a "best practices" musculoskeletal injury prevention program in nursing homes. Inj Prev 2004; 10(4):206-11.

37. Stetler CB, Burns M, Sander-Buscemi K, Morsi D, Grunwald E. Use of evidence for prevention of work-related musculoskeletal injuries. Orthop Nurs 2003; 22(1):32-41.

38. Nelson A, Lloyd JD, Menzel N, Gross C. Preventing nursing back injuries: redesigning patient handling tasks. AAOHN J 2003; 51(3):126-34.

39. Johnsson C, Kjellberg K, Kjellberg A, Lagerström M. A direct observation instrument for assessment of nurses' patient transfer technique (DINO). Appl Ergon 2004; 35(6):591-601.

40. Converso A, Murphy C. Winning the battle against back injuries. RN 2004; 67(2):52-7.

41. American Nurses Association position statement on elimination of manual patient handling to prevent work-related musculoskeletal disorders. Prairie Rose 2004; 73(4):18-9.

42. Owen BD. Preventing injuries using an ergonomic approach. AORN J 2000; 72(6):1031-6. 